DOI: $10.5455 / 2320-1770$. ijrcog000212

\title{
Late occurrence of a congenital diaphragmatic hernia complicating pregnancy: A case report
}

\author{
Anuradha Kakani*, Richa Choudhary, Jyoti Singh, Deepti Shrivastave
}

Department of Obstetrics \& Gynecology, AVBRH, Sawangi, Wardha, Maharashtra, India

Received: 24 November 2012

Accepted: 12 December 2012

*Correspondence:

Dr. Anuradha Kakani,

E-mail: anuradhakakani@gmail.com

\begin{abstract}
Diaphragmatic hernia complicating pregnancy is rare and results in a high fetal and maternal mortality particularly if early surgical intervention is not undertaken. A very high degree of suspicion in needed for diagnosis as the symptoms produced by this hernia are seen in normal pregnancy also. We present here a patient with CDH who became acutely symptomatic for the first time during the pregnancy and was managed successfully.
\end{abstract}

Keywords: Congenital diaphragmatic hernia (CDH), Incarceration, Foramina of Bochdaleck, Foramina of Morgagni

\section{INTRODUCTION}

Diaphragmatic hernias complicating pregnancy is rare and they can have catastrophic consequences. They can present to the surgeon as a life-threatening emergency or pose a management dilemma when detected incidentally. ${ }^{1}$ Ninety percent of these hernias occur on left side while right sided hernias are very rare as the caudate lobe of liver narrows the pleuroperitoneal canal and prevents herniation. The main life-threatening complications described, include respiratory distress, visceral obstruction, strangulation and gangrene of the herniated viscera, visceral perforation (spontaneous or thoracentesis-induced) and maternal death. ${ }^{2-4}$

We are reporting a rare case of right-sided congenital diaphragmatic hernia presented for the first time during the pregnancy.

\section{CASE REPORT}

A 21-year old unbooked primigravida with 24 weeks gestation came to casualty with the complaint of difficulty in breathing since 15 days pain in abdomen which was sharp, intermittent and colicky type since 10 days and vomiting (3-4 episodes) since one day. She had similar complaints at 4 months of amenorrhea which was mild and was attributed to pregnancy itself during her antenatal visits and no treatment was given.
On physical examination the patient was afebrile, hypotensive with tachycardia and dyspnoea. Chest auscultation demonstrated decreased air entry in the right lower thorax. Heart sounds were normal. Her abdomen was soft and with loss of normal liver dullness. Obstetric examination revealed that the fundal height corresponding to 24 weeks gestation with a single foetus. The fetal heart sound was present and no other significant findings on examination.

Laboratory findings showed leucocytosis, electrocardiogram showed sinus tachycardia. A nasogastric tube was placed and $200 \mathrm{~mL}$ gastric fluid was aspirated.

A chest X-ray suggested diaphragmatic hernia because of presence of air-fluid level in right mid zone and nonhomogeneous opacity in the right lower zone. Right lung was collapsed.

Chest ultrasound examination demonstrated dilated bowel loops in the right pleural cavity and pleural effusion and confirmed definitely the diagnosis of diaphragmatic hernia probably obstructed. Obstetric scan revealed single live intrauterine fetus of gestational age 23.4 weeks. Due to her unstable condition and because of concerns for ischemia of the herniated viscera, the patient was rushed to surgery. 


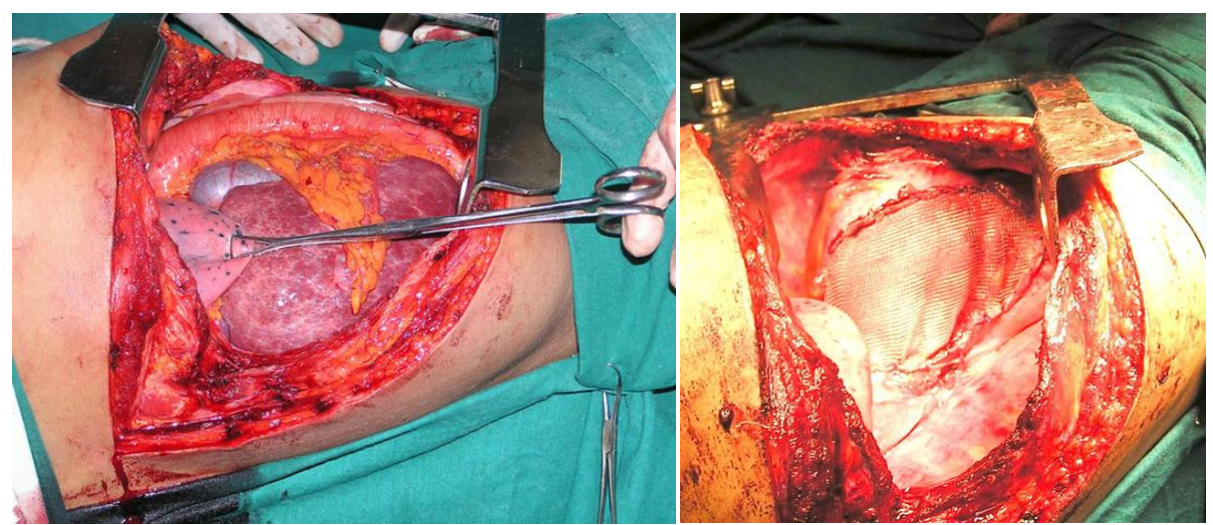

Figure 1: Intraoperative finding.

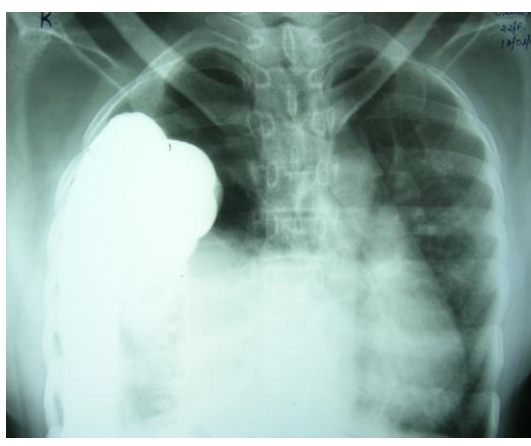

Figure 2: Preoperative X-ray.

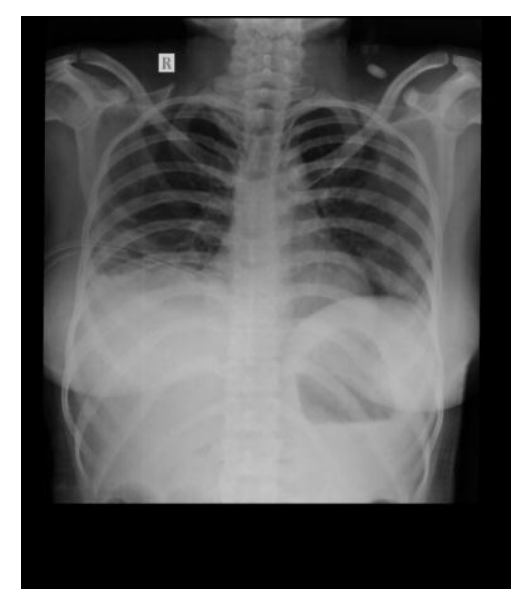

Figure 3: Postoperative X-ray.

Abdomen opened by a midline incision and thoracic cavity was exposed. The herniated small and large bowel loops were reduced. The defect of about 4 X $5 \mathrm{~cm}$ was closed with prolene mesh and sutured to the thoracic side of diaphragm. A segment of $15 \mathrm{~cm}$ of bowel loop was found gangrenous. Resection and anastomosis of the bowel was done and the gangrenous bowel was sent for histopathological examination (Figure 1) which confirmed gangrenous necrosis. Manipulation of the uterus was avoided during surgery. Fetal well-being was confirmed throughout the procedure by continuous fetal heart rate monitoring. After surgery, the patient was on ventilator for 24 hours and her complaints ceased immediately. X-ray findings improved dramatically (Figure 3). The fetal and uterine activities were monitored daily. On $3^{\text {rd }}$ post-operative day, unfortunately intra uterine demise occurred and patient was induced with misoprostol per vaginum and she aborted a male fetus of 500 grams. Post-operative period was uneventful and patient was discharged home on $15^{\text {th }}$ post-operative day.

\section{DISCUSSION}

Diaphragmatic hernias are divided into 2 categories: congenital defects and acquired defects. Congenital diaphragmatic hernias $(\mathrm{CDH})$ occur because of embryologic defects in the diaphragm. Most patients with $\mathrm{CDH}$ present early rather than late in life; however, a subset of adults may present late as it was undetected during childhood and may manifest later due to raised intraabdominal pressure as seen in our case. Acquired diaphragmatic hernias are due to trauma. ${ }^{5}$ When the defect manifest during pregnancy it may affect both the mother and fetus. This is due to incarceration or strangulation of intraabdominal structures.

Most diaphragmatic hernias occur on the left side of the body, but in our case the hernia was right sided. ${ }^{6}$ Symptoms in patients with $\mathrm{CDH}$ are mostly due to the effects of abdominal viscera within the pleural cavity and the commonest are chest pain and dyspnoea. Diminished breath sounds on the ipsilateral side are the most common physical finding. There may be signs of high or low mechanical ileus depending on which part of the gastrointestinal tract is herniated. ${ }^{6}$

A very high degree of suspicion in needed for diagnosis during pregnancy as the symptoms produced by this hernia are seen in normal pregnancy also. The failure of antacids, antispasmodics and dietary changes to relieve 
the symptoms especially in women with pregnancy should lead the physician to suspect gastrointestinal pathology. $^{7}$

Management of a patient with diaphragmatic hernia complicating pregnancy requires thorough assessment, close monitoring and preparedness for emergency surgery. The pregnant mothers run the risk of intestinal obstruction and strangulation as greater amount of viscera is displaced into the thorax by the enlarging viscera as seen in our case. Literature suggest that diaphragmatic hernia can be safely repaired in the antepartum period. ${ }^{8,9}$

Symptomatic patients presenting in first and second trimester should undergo operative repair. Corticosteroids for fetal maturity should be administered to the mother before surgery if the gestational age is between 24 and 34 weeks because of the risk of preterm delivery during or after surgery. The patients who had undergone repair of hernia during their first or second trimester can be allowed to deliver vaginally. Uterine contractions do not increase intraabdominal pressure and are unlikely to cause rupture at repair site. ${ }^{8}$ However, bearing down efforts can increase intraabdominal pressure which can be overcome by epidural anesthesia and assisted labor using vacuum or forceps. For symptomatic patients presenting during third trimester, elective cesarean section and hernia repair can be done simultaneously.

In our case, symptoms of cardio respiratory failure and bowel obstruction led us to urgent repair because further delay could be fatal for the mother and fetus but unfortunately we could not save the baby.

In conclusion, a high degree of suspicion is required for diagnosis of this rare but treatable condition.
Consideration should be given to operative repair in the second trimester if asymptomatic hernias are identified during pregnancy. As in our case the catastrophe could have been avoided had she not been misdiagnosed when she had similar complaints at 4 month amenorrhea.

\section{REFERENCES}

1. Stephenson BM, Stamatakis JD. Late recurrence of a congenital diaphragmatic hernia. Case report. Br J Obstet Gynaecol 1991;98:110-1.

2. Hill R, Heller MB. Diaphragmatic rupture complicating labor. Ann Emerg Med 1996;27:5224.

3. Watkin DS, Hughes S, Thompson MH. Herniation of colon through the right diaphragm complicating the puerperium. J Laparoendosc Surg 1993;3:583-6.

4. Fardy HJ. Vomiting in late pregnancy due to diaphragmatic hernia. Case report. $\mathrm{Br} \mathrm{J}$ Obstet Gynaecol 1984;91:390-2.

5. Kaloo PD, Studd R, Child A. Postpartum diagnosis of a maternal diaphragmatic hernia. Aust N Z J Obstet Gynaecol 2001;41:461-3.

6. Gimovsky ML, Schifrin BS. Incarcerated foramen of Bochdalek hernia during pregnancy. A case report. J Reprod Med 1983;28:156-8.

7. Lacayo L, Taveras JM 3rd, Sosa N, Ratzan KR. Tension fecal pneumothorax in a postpartum patient. Chest 1993;103:950-1.

8. Genc MR, Clancy TE, Ferzoco SJ, Norwitz E. Maternal Congenital Diaphragmatic Hernia Complicating Pregnancy. Obstet Gynecol 2003;102:1194-6.

9. Kurzel RB, Naunheim KS, Schwartz RA. Repair of Symptomatic Diaphragmatic Hernia during Pregnancy. Obstet Gynaecol 1988;71:869-71.

DOI: $10.5455 / 2320-1770$. ijrcog000212

Cite this article as: Kakani A, Choudhary R, Singh J, Shrivastave D. Late occurrence of a congenital diaphragmatic hernia complicating pregnancy: A case report. Int J Reprod Contracept Obstet Gynecol 2012;1:47-9. 